\title{
Editorial
}

\section{Antropología de la obesidad y de la diabetes gestacional}

En el curso de apenas dos siglos de vida independiente, nuestro hermoso país ha pasado de ser una colonia pobre de 900 mil habitantes, a una nación próspera de 16 millones. Junto con el espectacular aumento del ingreso per cápita, e incluso antes, han tenido lugar grandes mejorías en expectativa de vida y en reducción de mortalidad infantil, materna y perinatal. Como ha sucedido en otros países emergentes, aunque mucho más gradualmente, las calorías per cápita y el sedentarismo han aumentado, y con ellos, la prevalencia de diabetes tipo 2, obesidad y diabetes gestacional.

En este editorial, intentaremos dar algunas luces sobre el contexto histórico y antropológico en que estos fenómenos han tenido lugar, lo que nos permitirá entenderlo mejor, para así solucionarlos debidamente.

\section{RECORDANDO LA FISIOLOGÍA DE LA INSULINA}

Un adulto normal ingiere unas $2500 \mathrm{Kcal}$ al día, de las cuales el $40 \%$ (1000 Kcal) son en carbohidrato. Como cada gramo de éstos produce $4 \mathrm{Kcal}$, entonces esta persona ingiere 250 gramos de carbohidratos diarios, que son procesados rápidamente en el tubo digestivo hasta transformarse en glucosa, que es absorbida rápidamente y llega a la circulación sanguínea, alcanzando valores normales en sangre de 70 a $99 \mathrm{mg} / \mathrm{dL}$ (0,7-0,99 $\mathrm{g} / \mathrm{L}$ de plasma). Esta es la glucosa que estimula a las células beta del páncreas a producir insulina.

Las células beta producen insulina de dos maneras. Una producción basal (ya sea que se ingiera o no alimento) de 0,35 unidades $x \mathrm{Kg}$ de $\mathrm{Peso}^{-1} \times$ día $^{-1}$. Además, una producción prandial de insulina, que ocurre con cada comida, y que equivale a aproximadamente 0,1 unidades $\times \mathrm{Kg}$ de Peso ${ }^{-1} \times$ comida $^{-1}$ (1). La producción prandial ocurre gracias a que la célula beta es capaz de medir tanto la glicemia como la primera derivada de glicemia respecto a tiempo (2). Una vez en la sangre, la insulina es llevada a los dos "órganos blanco" principales: las células del tejido adiposo y las células de los músculos, estas últimas grandes consumidoras de glucosa.

Las células de los tejidos adiposo y muscular tienen receptores específicos para insulina, la que se une a la porción extracelular del receptor, haciendo que éste modifique su forma. En ese momento, la porción intracelular del receptor adquiere capacidad de kinasa (enzima fosforilante), haciendo que una molécula de fosfato $\left(\mathrm{H}_{3} \mathrm{PO}_{3}{ }^{-}\right)$se combine con el aminoácido tirosina. El receptor así fosforilado hace que se incorpore fosfato a otra molécula, llamada insulin receptor substrate-1 (IRS-1).

El IRS-1 fosforilado, a su vez, se une a varias proteínas llamadas proteínas SH2 (Figura 1), una de las cuales es la fosfatidil-inositol-3 kinasa (PI-3 Kin). Pues bien, el ahora complejo [IRS-1 + PI-3 Kin] se une a la proteína RAB-4, encargada de anclar las microvesículas revestidas de membrana, que contienen a las moléculas transportadoras de glucosa Glut-4, que efectúan transporte facilitado de glucosa desde el exterior de la célula a su interior (Figura 1).

Sin embargo, no hay que subestimar el efecto del ejercicio físico. Durante el ejercicio, el transportador Glut-4 también es traslocado hacia la membrana de la célula muscular, sin intervención de insulina. Por ejemplo, una simple caminata permite la entrada de 100 gramos de glucosa por hora a los músculos. Un ejercicio violento (correr, nadar, remar) permite la entrada, como máximo, de 200 gramos de glucosa por hora.

No hay que olvidar que además de su acción sobre el trasporte de glucosa, la insulina estimula la síntesis de proteína y grasa, e interviene en el crecimiento celular y expresión genética (Figura 2). En este sentido, la insulina se comporta como una hormona anabólica. En realidad, la insulina es la más anabólica de todas las hormonas. 


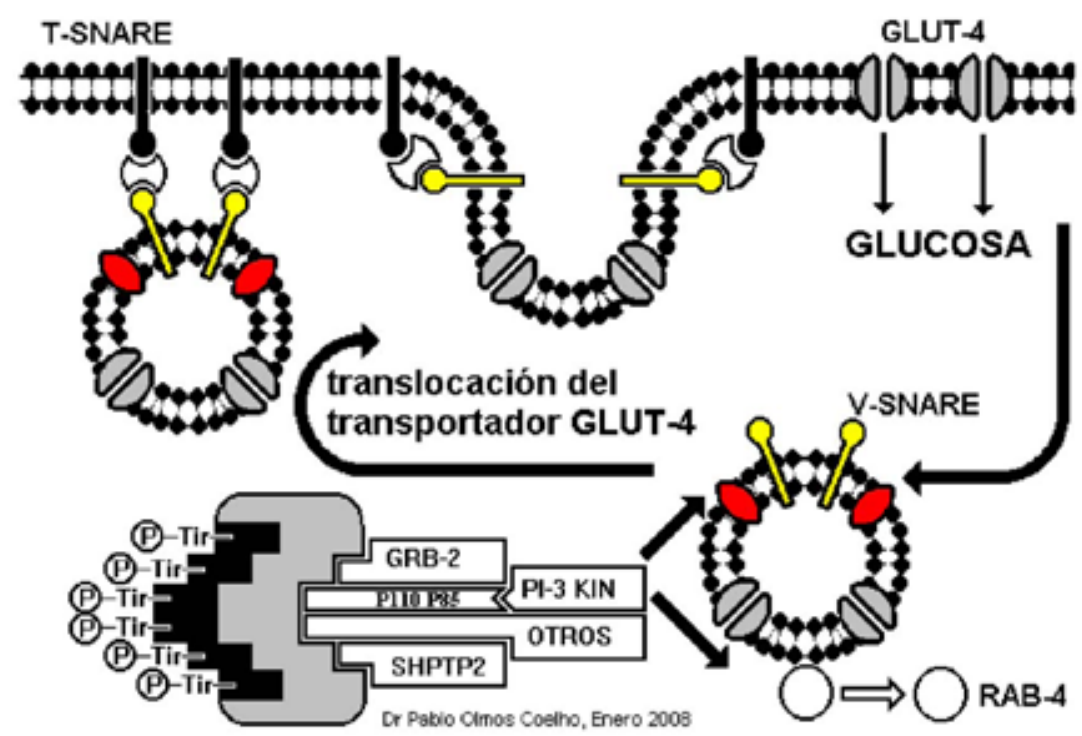

Figura 1. Acción de la Insulina. El complejo IRS-1+ Fosfatidil Inositol-3 Kinasa (IRS-1+PI-3 KIN) suelta a la vesícula que contiene el Glut-4 de su anclaje (RAB-4), y permite la 'traslocación' del transportador Glut-4 a la membrana plasmática de la célula, donde el T-Snare y el V-Snare se unen y, abriendo la vesícula, permiten que el Glut-4 transporte glucosa al interior de la célula.

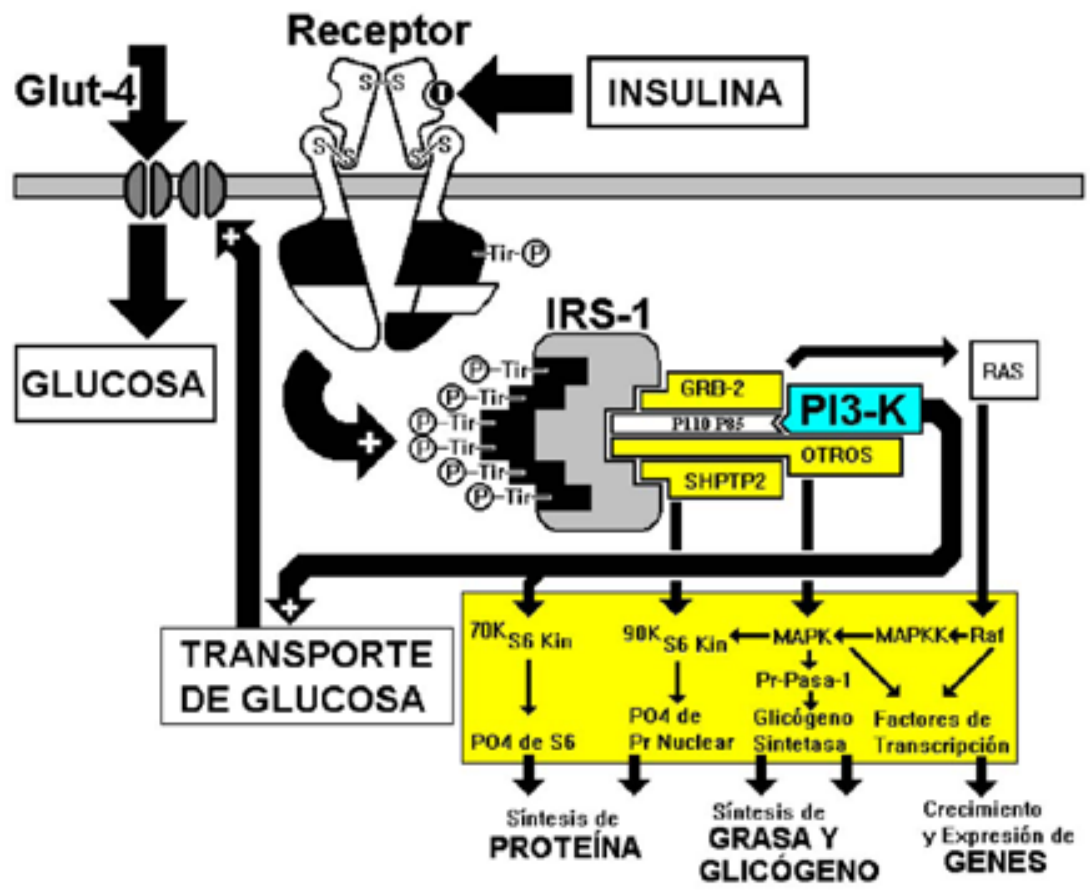

Figura 2. Acción de la Insulina. Además de su acción en el transporte de glucosa al interior de las células musculares y adiposas, la insulina actúa a otros niveles, estimulando la síntesis de proteínas, grasa y glicógeno, y también la expresión genética. 


\section{RESISTENCIA INSULÍNICA}

Hace veinte mil años ocurrió el más reciente (y no será el último) período glacial. El consiguiente aumento de las masas de hielo de los glaciares terrestres y de Groenlandia y la Antártica "secuestraron" un enorme volumen de agua, dando como resultado un importante descenso del nivel del mar. Como consecuencia, la línea costera de todos los continentes se amplió significativamente (Figura 3). En el caso del tricontinente americano, el mar del estrecho de Bering (entre Alaska y Asia) fue sustituido por un puente de tierra firme, que se mantuvo por unos cinco mil años, al que se le ha dado el nombre de "Beringia" $(3,4)$. Durante ese período, se produjeron varias oleadas migratorias desde Asia nororiental hacia las Américas, vía Beringia. Estos seres humanos asiáticos no sólo se establecieron en Alaska, sino que durante los siguientes siglos continuaron su marcha hacia el sur, constituyendo una de las bases de la formación de los pueblos aborígenes de norte, centro y Sudaméri- ca. Para que este largo viaje tuviera lugar, muchas generaciones de migrantes tuvieron que atravesar extensos glaciares que entonces cubrían los territorios que actualmente son Alaska, Canadá, los grandes lagos de Norteamérica y parte de Sudamérica. Sólo algunos de estos migrantes tuvieron las características genéticas y metabólicas que les permitieron resistir el hambre y el agotamiento físico. Es decir, a medida que estos pueblos de origen asiático descendían hacia el sur, aquellos que no tenían adaptaciones al hambre y al esfuerzo físico sostenido iban quedando muertos, o incapaces de reproducirse, en el camino. Gradualmente entonces, con el paso de centenares de generaciones, se fue seleccionando un tipo de individuo con un genotipo capaz de regular su metabolismo en el sentido del "ahorro de energía", que les permitió seguir sobreviviendo por los siguientes miles de años, en que muchos de ellos siguieron siendo "cazadores-recolectores" (es decir, sin alimentación regular asegurada) y otros aprendieron lentamente a practicar la agricultura.

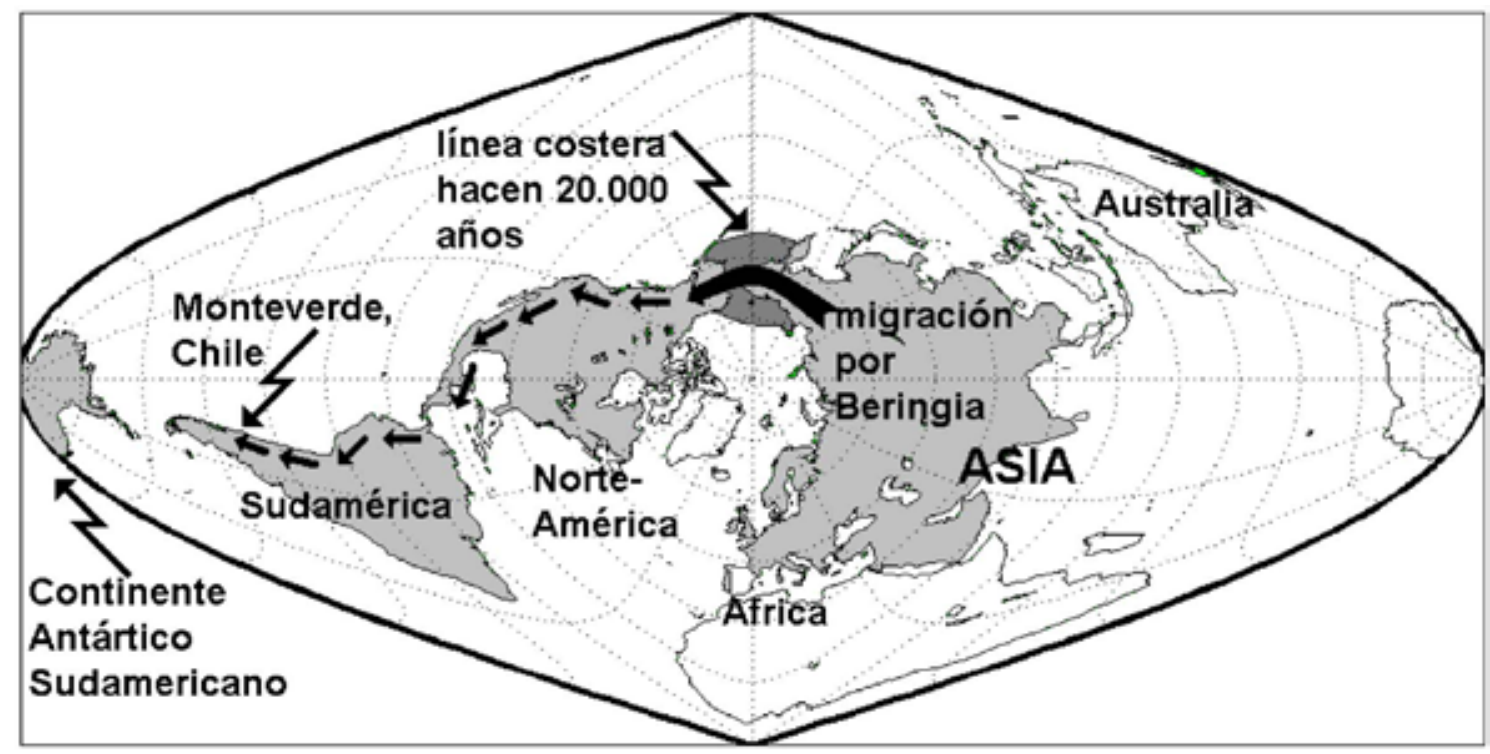

Figura 3. Mapa en proyección sinusoidal (Sur-Norte-Sur), que respeta las superficies relativas de los continentes. Hace veinte mil años, en el último período glacial, el nivel del mar bajó muchos metros, produciéndose un puente de tierra en la zona del actual estrecho de Bering, entre Asia y Alaska, llamado "Beringia". Vea el texto para comprender el impacto que esta migración tuvo en la resistencia insulínica de los aborígenes de América $(3,4)$. 
El lector estará preguntándose qué relación puede tener esta migración que ocurrió hace miles de años, con el tema de la resistencia insulínica y la obesidad. Para acercarnos a la respuesta, debemos dar un salto hasta comienzos del siglo veinte. ¿Qué había ocurrido? Pues bien, al cabo de miles de años de perfeccionamiento progresivo de la agricultura, a fines del siglo XIX la actitud de los países europeos respecto de la alimentación era optimista. Sin embargo, entre 1899 y 1902, la guerra de Transvaal ("Guerra de los Boers") entre Inglaterra y los Sudafricanos de origen holandés, sólo pudo terminar con la internación forzada, por parte de los ingleses, de las esposas e hijos de los soldados Boers en los eufemísticamente bautizados "campos de concentración", donde miles murieron de hambre, agotamiento y enfermedad. Los ingleses hicieron esto con el pretexto de evitar que los soldados Boers tuvieran el apoyo de sus familias que quedaban a cargo de sus haciendas. Posteriormente, estos campos de concentración, esclavización y exterminio serían extensamente utilizados en la Unión Soviética (19171990), en Europa ocupada por los alemanes (19351945) y otros países.

Cuando las bien alimentadas tropas de Estados Unidos invadieron Europa occidental (1944-1945), observaron los efectos del hambre en los campos de concentración. En consecuencia, durante los años de la postguerra (1945-1950), tuvo lugar a nivel mundial un renovado interés científico en los fenómenos de la hambruna y la realimentación $(5,6)$. En particular, era de interés descubrir por qué algunas personas pudieron sobrevivir a condiciones extremas de hambre y sobrecarga esclavizante de trabajo.

Fue en este contexto que a comienzos de la década de 1960, se acuñó el término "genotipo ahorrativo", o "thrifty genotype" $(6,7)$, el cual codificaría un "fenotipo ahorrativo", con tres características principales, a saber: a. Metabolismo súper eficiente, ahorrador de energía; c. Adipogenicidad, propensión a la acumulación rápida de grasa, y c. Fisiológicamente alerta, capaz de frenar procesos fisiológicos no esenciales para la supervivencia inmediata (6).

¿Cómo se expresaría este fenotipo ahorrativo? A través de la resistencia insulínica, donde existiría un bloqueo parcial en uno o más de los eventos post-receptor en la acción de la insulina en las células musculares y adiposas. Específicamente, el complejo [IRS-1 + PI3K] que habíamos mencionado en la Figura 2, tendría un grado parcial de disminución en su capacidad para "traslocar" el transportador Glut-4. Como resultado (Figura 4), se haría menos eficiente la entrada de glucosa a la célula, de modo que las células beta del páncreas se verían obligadas a aumentar su producción de insulina (hiperinsulinemia) para así estimular aún más los receptores y de este modo "compensar" la resistencia. La filosofía de esta resistencia insulínica consiste, por un lado, en aumentar la producción basal de insulina, y por otro, estimular las vías anabólicas de la acción insulínica sin producir hipoglicemia. Como resultado de lo primero, se reduce la lipolisis y se incrementa la lipogénesis, y como resultado de lo segundo se estimula la síntesis de proteína, grasa y glicógeno, el crecimiento celular y la expresión genética. Esta resistencia insulínica "étnica" entendida ahora como un fenotipo ahorrativo, explica entonces cómo algunas personas pudieron sobrevivir, y continúan haciéndolo hoy, a los campos de concentración, esclavización y exterminio, que todavía existen.

En efecto, este fenotipo ahorrativo fue muy útil durante los centenares de miles de años en que el ser humano fue cazador-recolector, que comía bien una vez a la semana (debiendo acumular reservas de grasa y proteína), y pasaba el resto del tiempo caminando y persiguiendo animales mientras su metabolismo trataba de ahorrar energía. Sin embargo, en la época actual la agricultura intensiva y la vida sedentaria con alimentación asegurada están haciendo que la resistencia insulínica ya no favorezca la supervivencia, sino que por el contrario, ésta acelere el desarrollo de obesidad, hiperinsulinemia, dislipidemia, hipertensión y diabetes tipo 2. En la sección siguiente, veremos de qué manera incide la resistencia insulínica en la fisiopatología y la bioquímica de la diabetes mellitus tipo 2 .

\section{LA EPIDEMIA GLOBAL DE DIABETES MELLITUS TIPO 2 Y DE OBESIDAD}

En los últimos años del siglo XX se comenzó a perfilar una situación nueva y alarmante. La OMS declaró la "epidemia global" de diabetes tipo 2 al observarse que la enfermedad afectaba a más de un $2 \%$ de la población mundial (8). Este estado de cosas, sumado a una tendencia universal al diagnóstico de la diabetes tipo 2 a edades cada vez más precoces (9), ha hecho que durante la última década esta enfermedad haya ido constituyendo cada vez más en un problema de salud en la población en general. Es más, en la última Encuesta Nacional de Salud de Chile (10), la diabetes tipo 2 afecta al 10 por ciento de los adultos, sumando 1,2 millones de personas.

Como dice su definición actual, la diabetes tipo 2 puede ir desde resistencia a la insulina predominante con deficiencia relativa de insulina, hasta un déficit de secreción de insulina predominante con o sin resistencia a la insulina. 


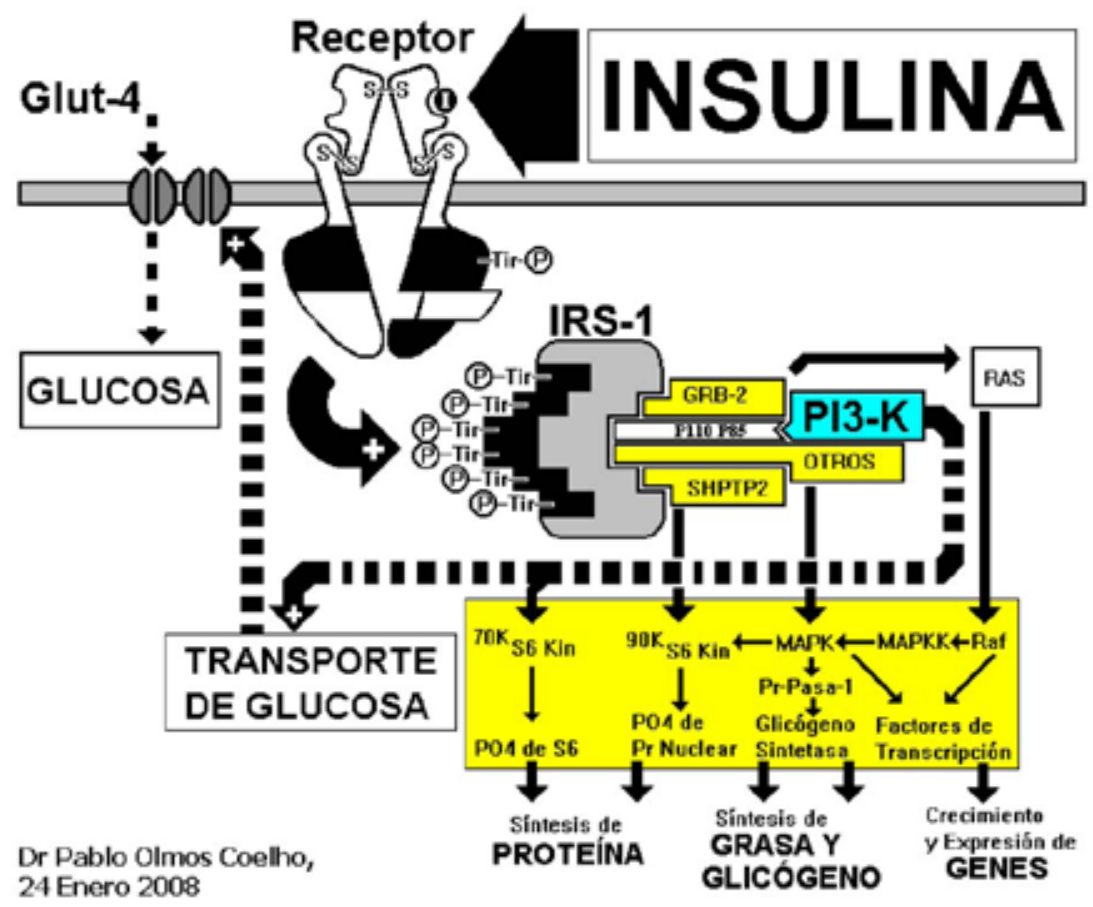

Figura 4. Hipótesis de la resistencia insulínica "étnica". Un bloqueo parcial a nivel [IRS-1+PI3-K] hace menos eficiente el transporte de glucosa al interior de la célula muscular y adiposa. Para compensar, el páncreas aumenta su producción de insulina, la que estimula la síntesis de proteína, grasa, glicógeno y la expresión genética sin producir hipoglicemia. Compare este dibujo con el de la Figura 2.

¿Por qué se ha hecho tan frecuente la diabetes tipo 2 en Chile y en el mundo? ¿Qué ocurrió en la segunda mitad del siglo XX que hizo aumentar de tal modo la frecuencia de diabetes tipo 2 ?

Hay varias razones. Primero, dejemos establecido que un $20 \%$ de la población mundial (el quintil de mayor resistencia) tiene algún grado de resistencia insulínica "étnica". Como se ve en la Figura 5, mientras la resistencia insulínica sea compensada con una adecuada producción de insulina, no tiene lugar diabetes tipo 2. Sin embargo, con el correr de los años, muchas personas se hacen cada vez más sedentarias, lo que incrementa la resistencia a la insulina. Además, la acumulación de tejido adiposo por el sedentarismo hace que aquel produzca una serie de citokinas, entre ellos el factor de necrosis tumoral alfa (TNF- $\alpha$ ), lo que hace aumentar aún más la resistencia insulínica $(11,12)$. Específicamente, el TNF- $\alpha$ reduce la captación de glucosa dependiente de insulina en células adiposas y musculares, y reduce la fosforilación tanto del IRS-1 y de otras moléculas en la cadena post-receptor de la insulina (11).
Finalmente entonces, las curvas de resistencia y de producción insulínica se cruzan, de modo que la insulina se hace insuficiente, apareciendo la diabetes tipo 2. Como puede verse también en la Figura 5, después del comienzo de la diabetes tipo 2, la secreción de insulina puede aumentar su ritmo de disminución, debido al efecto tóxico que tiene la hiperglicemia sobre el funcionamiento de las células beta.

Como durante los últimos 100 años ha ocurrido un aumento global en las tasas de sedentarismo y obesidad, no resulta entonces sorprendente que no sólo esto haya hecho aumentar la prevalencia de diabetes tipo 2 , sino que también haya provocado un progresivo adelantamiento en la edad de comienzo de ésta. Precisamente, una de estas situaciones en que la diabetes comienza a edad temprana es en el caso de la diabetes mellitus gestacional, que afecta a una proporción cada vez mayor de mujeres embarazadas. 

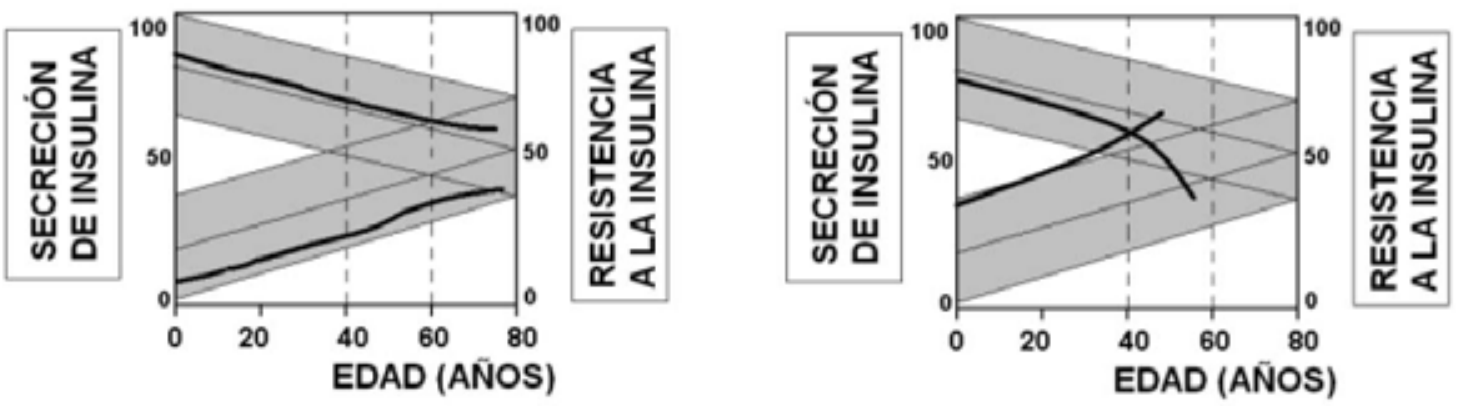

Figura 5. Curvas de secreción y resistencia a la insulina. A la izquierda, una persona sin resistencia insulínica quien, no importa cuánto envejezca, nunca tendrá diabetes tipo 2. A la derecha, una persona con resistencia insulínica, la que al aumentar con la edad, llega un momento en que la secreción de insulina se hace insuficiente y aparece diabetes tipo 2.

\section{LA DIABETES GESTACIONAL Y LA RESISTEN- CIA INSULÍNICA ÉTNICA}

El primer caso de diabetes gestacional fue descrito en la tesis de Doctor en Medicina de Heinrich G. Bennewitz en el año 1824 (13). Se trataba de una embarazada que desarrolló diabetes mellitus sintomática durante la gestación, y cuyos síntomas (poliuria, polidipsia) y signos (glucosuria de 125 $\mathrm{g} / \mathrm{L}$ ) desaparecieron después del parto.

Después de 1824, este caso clínico no cayó en el olvido. Entre 1825 y 1947 varias pacientes similares fueron identificadas, acuñándose entonces el término "glucosuria benigna del embarazo" (14). Sin embargo, ya en 1949, Gilbert (15) observó que las mujeres a las cuales se les diagnosticaba en la quinta década de la vida lo que hoy llamamos diabetes mellitus tipo 2, habían tenido una "mala historia obstétrica", con incidencias desproporcionadamente altas tanto de mortalidad perinatal (2-7 veces lo normal), así como de fetos mayores que 4 kilos (4,2 veces por sobre los embarazos normales) y mayores que 5 kilos ( 55 veces sobre la tasa normal) (15,16). Así entonces, a partir de 1949, el término "glucosuria benigna del embarazo" dejó de ser aplicable. Esto llevó a acuñar el término "prediabetes en el embarazo", que en 1954 cambió a "diabetes meta-gestacional" (17). Finalmente, en 1964, la diabetes mellitus gestacional (DMG) emergió como subtipo de Diabetes Mellitus (18). La tendencia de la incidencia de DMG es de un aumento exponencial en todo el mundo desde una media de $4 \%$ en la década de 1980 , hasta cifras cercanas al 20\% $(19,20)$ en la actualidad (Figura 6).

$$
\begin{aligned}
& r=0,568 \\
& p<0,01
\end{aligned}
$$

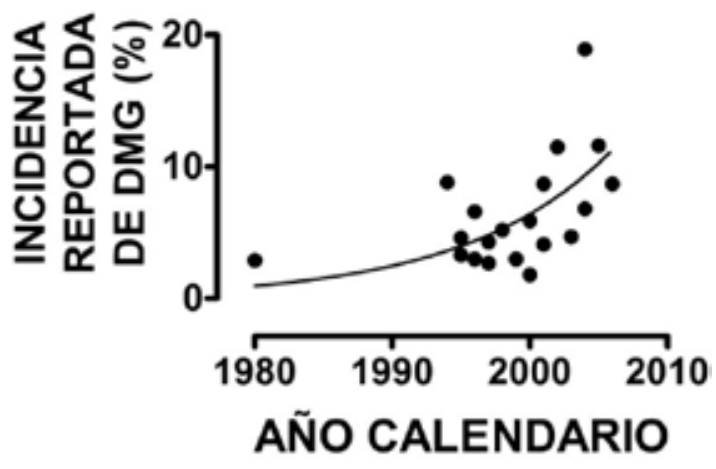

Figura 6. Aumento de la incidencia mundial de diabetes gestacional desde 1980 a la fecha $(19,20)$.

Tal como habíamos adelantado más arriba, la diabetes gestacional es una situación de embarazo con resistencia insulínica pregestacional. En efecto, con la progresión del embarazo se incrementan los niveles de cortisol y lactógeno placentario, especialmente a partir de las 22 a 24 semanas de gestación, lo que lleva a un incremento sostenido de la resistencia insulínica materna, la que se compensa con mayor secreción de insulina, que llega hasta 3 veces los niveles normales. Lo anterior se manifiesta con un menor nivel de glicemia en ayuno y tendencia a su aumento postprandial. 
En la embarazada normal este mecanismo de compensación permite mantener una adecuada homeostasis en el metabolismo de los carbohidratos. Sin embargo, en algunas madres gestantes se produce una insuficiencia relativa al sumarse a la resistencia insulínica pregestacional aquella producida por las hormonas placentarias. El resultado es una diabetes gestacional (Figura 7). Una vez terminado el embarazo, las hormonas placentarias desaparecen, y la resistencia insulínica vuelve a los valores previos de la paciente. Sin embargo, el solo hecho de haber tenido diabetes gestacional indica que las curvas de secreción y resistencia estaban peligrosamente cercanas (20).

En diversas etnias a lo ancho del mundo, la incidencia acumulativa de diabetes tipo 2 después de haber tenido DMG es de $40-50 \%$ a 5 años y se estabiliza en $70 \%$ después de los 10 años de seguimiento (21). Por esta razón, en la visita posparto, es necesario instruir a la paciente respecto de la utilidad del ejercicio físico aeróbico (caminata, natación), y una dieta saludable, con el fin de mantener normal la sensibilidad insulínica y un índice de masa corporal de $20-25 \mathrm{~kg} / \mathrm{m}^{2}$, único modo de reducir el riesgo de diabetes tipo 2. Como puede verse en la Figura 7, el solo hecho de haber tenido DMG indica que las curvas de secreción de insulina y resistencia a la insulina se hallan peligrosamente cercanas, y el único modo de alejarlas es la combinación de ejercicio aeróbico, dieta y peso normal.

\section{REFLEXIÓN}

En el año 1976 se descubrió el establecimiento
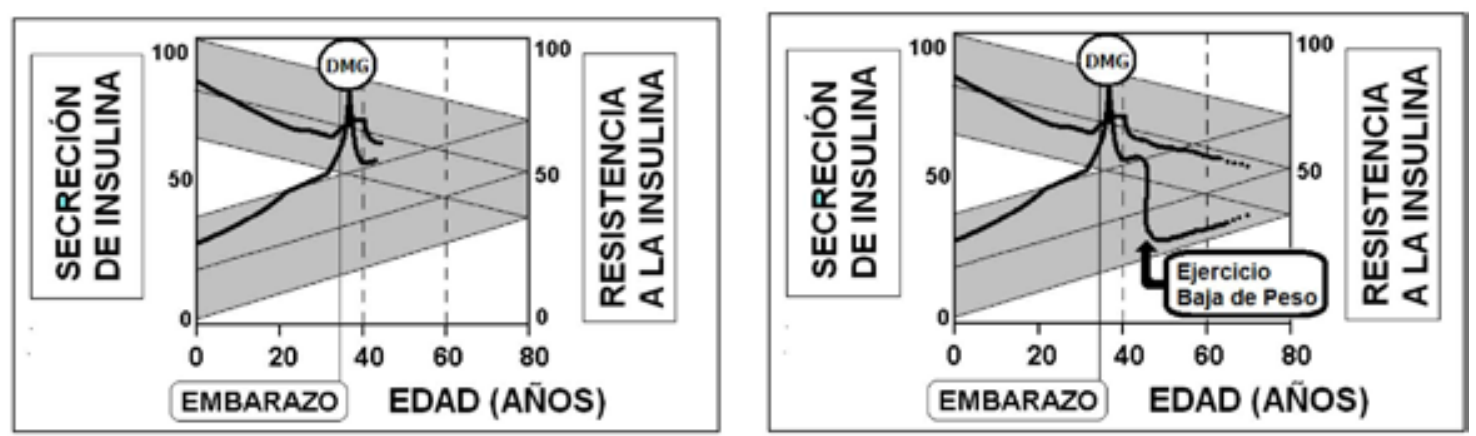

Figura 7. A la izquierda: observe como en una mujer que ya arrastraba algún grado de resistencia insulínica antes del embarazo, el aumento de resistencia gestacional no logra ser compensado con una insuficiente aumento de secreción insulínica. El resultado es una diabetes gestacional. A la derecha: con ejercicio y baja de peso post parto, lograremos alejar las curvas de secreción y de resistencia, evitando así la diabetes tipo 2. 

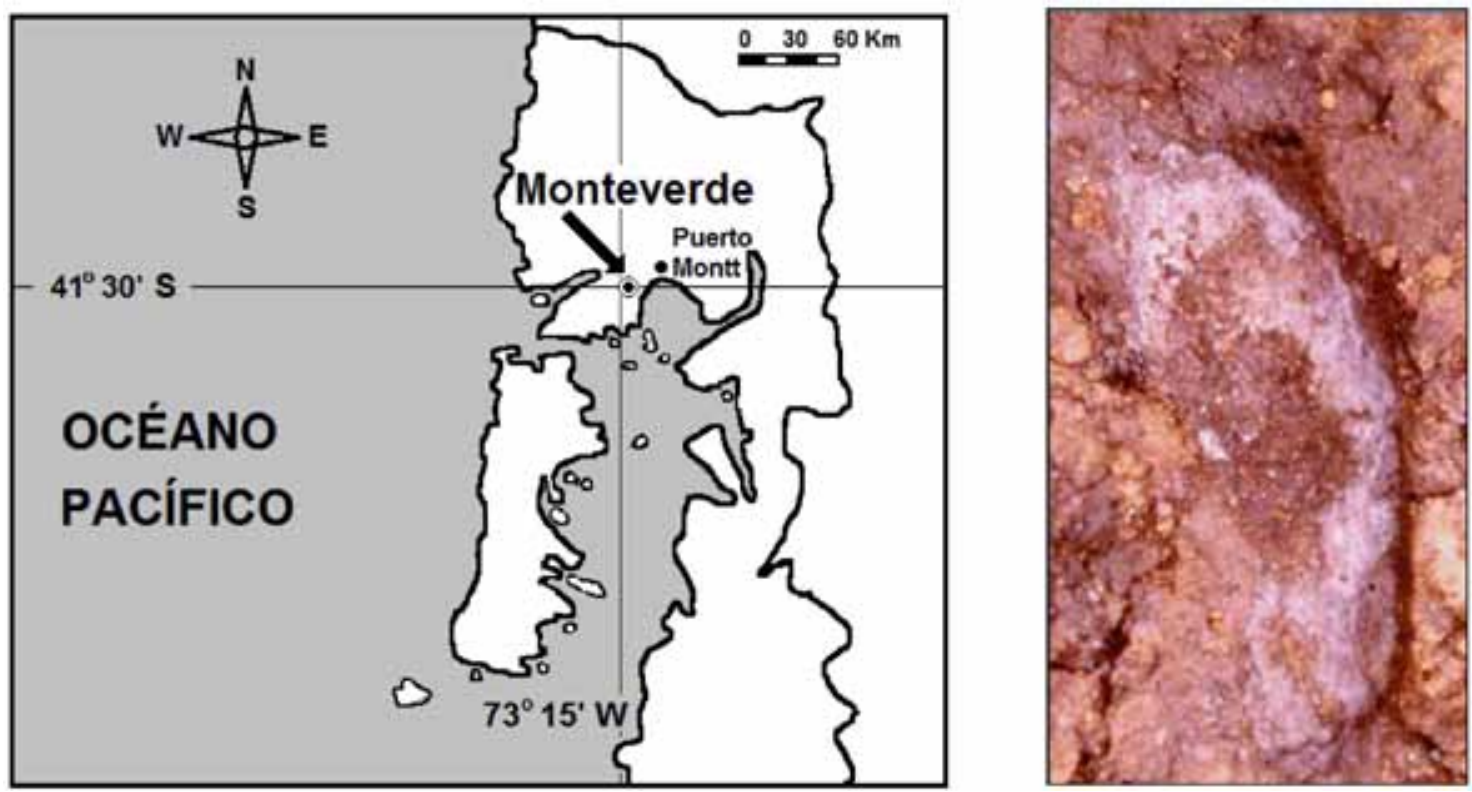

Figura 8. A la izquierda, mapa de la Región de los Lagos, Chile, mostrando que Monteverde está ubicado a $15 \mathrm{Km}$ al Sur-Este de Puerto Montt. A la derecha, huella del pie de un niño de hace 14.600 años atrás, en Monteverde (24).

A primera vista, este desafío puede parecer excesivamente difícil para el lector. Vale la pena, entonces, recordar parte del discurso de John W. Gardner (1912-2002) al aceptar el cargo de secretario de salud, educación y bienestar de Estados Unidos: “...damas y caballeros, nos enfrentamos a una serie de grandes oportunidades, hábilmente disfrazadas de problemas insolubles..”. (25).

Pablo Olmos Coelho. MSc. Departamento de Nutrición, Diabetes y Metabolismo. Escuela de Medicina.

Pontificia Universidad Católica de Chile. Proyecto FONDECYT Nº 1120682.

\section{REFERENCIAS}

1. Howorka K. Functional insulin treatment, principles, teaching approach and practice. 1996. Springer-Verlag, Berlin Heidelberg. pp 52-57.

2. Albisser AM, Leibel BS, Ewart TG, Davidovac Z, Botz CK, Zingg W. An artificial endocrine pancreas. Diabetes 1974;23:389-96

3. University of Illinois (2007, October 29). New ideas about human migration from Asia to Americas. ScienceDaily. Disponible en: http://www.sciencedaily.com/ releases/2007/10/071025160653.htm. Consultado el 24 de enero de 2008.
4. Malhi RS, Eshleman JA, Greenberg JA, Weiss DA, Schultz-Shook BA, Kaestle FA, Lorenz JG, Kemp BM, Johnson JR, Glenn-Smith D. The structure of diversity within new world mitocondrial DNA haplogroups: Implications for the prehistory of North America. Am J Hum Genet 2002;70:905-19.

5. Keys AJ, Brozek J, Henschel O, Michelson O, Taylor HL. The biology of human starvation. 1950, University of Minnesota Press, Minneapolis, MN, USA.

6. Prentice AM, Rayco-Solon P, Moore SE. Insights from the developing world: thrifty genotypes and thrifty phenotypes. Proc Nutr Soc 2005;64:153-61.

7. Neel JV. Diabetes mellitus: A "thrifty genotype" rendered detrimental by "progress". Am J Hum Genet 1962;14:353-62.

8. Zimmet P, Alberti KGMM, Shaw J. Global and societal implications of the diabetes epidemic. Nature 2001;414:782-6.

9. Feig DS, Palda VA. Type 2 diabetes in pregnancy: a growing concern. Lancet 2002;359:1690-2.

10. MINSAL-Chile. Encuesta Nacional de Salud 2010. Disponible en: http://www.hospitalsoterodelrio.cl/ home/files/destacados/Informe_ENS\%202009_2010. pdf. Consultado el 31 enero 2014.

11. Ledgerwood EC, Prins JB. Tumour necrosis factor alpha. En: Marshall SM, Home PD and Rizza RA, editors. The Diabetes Annual-12. 1999 Elsevier Science B.V., Amsterdam, The Netherlands. pp 161180.

12. Kirwan JP, Haungel-De-Mouzon S, Lepercq J, Challier J-C, Huston-Presley L, Friedman JE, Kalhan SC, 
Catalano PM. TNF- $\alpha$ is a predictor of insulin resistance in human pregnancy. Diabetes 2002;51:2207-13.

13. Bennewitz HG. De diabetes mellito graviditatis symptomate: Diss. Inaug. Med. 1824. Tesis de Doctorado en Medicina. Bayerichen Staatsbibliothek, Ludwigstrasse $N^{\circ} 16,80593$ München, Alemania.

14. Barns HHF, Morgans ME. Prediabetic pregnancy. Br J Obstet Gynecol 1948;55:449-54.

15. Gilbert JAL. The association of maternal obesity, large babies, and diabetes. Br Med J 1949;1:702-4.

16. Miller HC, Hurwitz D, Kuder K. Fetal and neonatal mortality in pregnancies complicated by diabetes meIlitus. JAMA 1944;124:271-5.

17. Hadden DR. A historical perspective on gestational diabetes. Diabetes Care 1998;21(Supplement 2):B3-B4.

18. O'Sullivan JB, Mahan CM. Criteria for the oral glucose tolerance test in pregnancy. Diabetes 1964;13:278-85.

19. Hunt KJ, Schuller KL. The increasing prevalence of diabetes in pregnancy. In: Conway DL and Rayburn WF, editors. Diabetes in Pregnancy. Obstet Gynecol Clin North Am 2007;34:174-99.

20. Olmos P, Belmar C. Capítulo 49. Diabetes y Embarazo. En: Pérez-Sánchez A, Donoso E, editores. OBS-
TETRICIA. Cuarta Edición 2011. Editorial Mediterráneo, Santiago, Chile. pp 1019-68.

21. Kim C, Berger DK, Chamany S. Recurrence of gestational diabetes mellitus. A systematic review. Diabetes Care 2007;30:1314-9.

22. Meltzer DJ. Monte Verde and the Pleistocene peopling of the Americas. Science 1997;276:754-5.

23. Dillehay TD, Ramírez C, Pino M, Collins MB, Rossen J, Pino-Navarro JD. Monte Verde: Seaweed, Food, Medicine, and the Peopling of South America. Science 2008;320:784-6.

24. David F. Salisbury. Photograph of a human footprint. Monteverde, Chile, Publicado el 8 de mayo de 2008. Disponible: http://www.vanderbilt.edu/exploration/stories/monteverde.html. Consultado el 27 de enero de 2014.

25. Gardner JW. Secretary of Health, Education and Welfare for President L.B. Johnson. "We are all faced with a series of great opportunities brilliantly disguised as unsolvable problems". Citado por "izquotes". Izquotes.com/quote/328452. Consultado el 3 de febrero de 2014. 